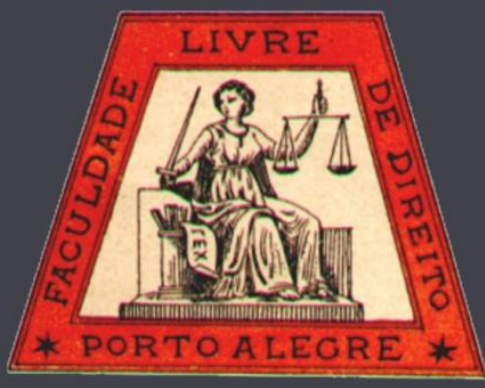

\title{
A Lei Anticorrupção e o Princípio da Boa-fé: desafios da ética corporativa nos contratos empresariais
}

Anti-corruption Act and the Principle of Good Faith: challenges of corporate ethics in business contracts

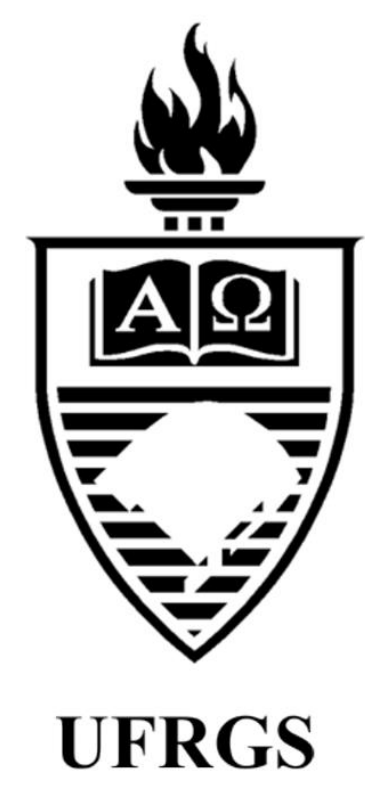

Juliana Oliveira Nascimento

Centro Universitário Autônomo do Brasil

Rosalice Fidalgo Pinheiro

Universidade Federal do Paraná 


\title{
A Lei Anticorrupção e o Princípio da Boa-fé: desafios da ética corporativa nos contratos empresariais
}

\author{
Anti-corruption Act and the Principle of Good Faith: challenges of corporate ethics in business
}

contracts

Juliana Oliveira Nascimento*

Rosalice Fidalgo Pinheiro**

\section{REFERÊNCIA}

NASCIMENTO, Juliana Oliveira; PINHEIRO, Rosalice Fidalgo. A Lei Anticorrupção e o Princípio da Boa-fé: desafios da ética corporativa nos contratos empresariais. Revista da Faculdade de Direito da UFRGS, Porto Alegre, $\mathrm{n}$. 35, p. 199-217, dez. 2016.

\section{RESUMO}

O presente artigo tem por objeto a Lei $\mathrm{n}^{\circ} 12.846 \mathrm{de} 1^{\circ} \mathrm{de}$ agosto de 2013, denominada usualmente de "Lei Anticorrupção" e sua relação com os contratos empresariais. Ocorre que à atividade empresarial mostrase imprescindível a criação de normas éticas internas em suas organizações e não apenas no trato com a administração pública. A "Lei Anticorrupção" encontra seus fundamentos nos princípios democrático e da moralidade administrativa, presentes na Constituição da República, enunciando seu aspecto ético. Nesta perspectiva, indaga-se se este aspecto também deve nortear os contratos de Direito Privado, notadamente, os contratos empresariais. Para tanto, recorre-se aos princípios contratuais, dentre os quais o da boa-fé consagrado pelo Código Civil de 2002. O desenvolvimento assumido por este princípio no Direito brasileiro permite delinear uma ética corporativa, como um dos mais notáveis desafios aos contratos empresariais. Para tanto, utiliza-se do método dedutivo e do procedimento de pesquisa bibliográfico, enunciando um plano de trabalho que se divide em três partes: a primeira trata da Lei n. $^{\circ} 12.846$, de $1^{\circ}$ de agosto de 2013 e seus fundamentos constitucionais; a segunda trata do princípio da boa-fé e a ética corporativa que dele deriva; e a terceira apresenta a ética corporativa como um novo desafio para os contratos empresariais.

\section{PALAVRAS-CHAVE}

Lei Anticorrupção. Ética Corporativa. Princípio da Boa-

\section{ABSTRACT}

The article has as its object the Act No. 12,846 of August 1, 2013, usually called "Anticorruption Act" and its relations with business contracts. It happens that to the business activity appears to be essential the creation of internal ethical standards in the organizations, and not only when dealing with the public administration. The "Anticorruption Act" finds its foundations in the democratic and in the administrative morality principles, present in the Constitution of the Republic, enunciating its ethical aspect. In this perspective, it is questioned if this aspect should also guide the private law contracts, notably, business contracts. For this purpose, it resorts to contractual principles, among which the good faith as established in the Civil Code of 2002. The remarkable development undertaken by this principle in Brazilian Law allows to outline a corporate ethics, as one of the greatest challenges to contracts business. To that end, it uses the deductive method and bibliographic research procedure, enunciating a work plan which is divided into three parts: the first deals of Act No. 12,846, August 1, 2013 and its constitutional foundations; the second deals with the principle of good faith and corporate ethics that stems from it; and the third presents the corporate ethics as a new challenge that presents itself to the business contracts.

\section{KEYWORDS}

Anti-Corruption Act. Corporate Ethics. Principle of Good

\footnotetext{
${ }^{*}$ Professora da Academia Brasileira de Direito Constitucional e do Curso de Compliance Público do Instituto Arc (São Paulo). Master of Laws - International Business Law pela Steinbeis University Berlin (Alemanha) e Mestranda em Direitos Fundamentais e Democracia (Centro Universitário Autônomo do Brasil, Paraná). Advogada.

** Professora Adjunta de Direito Civil da Faculdade de Direito da Universidade Federal do Paraná - UFPR e do curso de Mestrado do Centro Universitário Autônomo do Brasil, Paraná. Doutora em Direito das Relações Sociais (Universidade Federal do Paraná - UFPR, 2004) e estágio pós-doutoral na Université Paris 1 - Panthéon-Sorbonne.
} 
Fé. Contratos Empresariais.

Faith. Business Contracts.

\section{SUMÁRIO}

Introdução. 1. Fundamentos constitucionais da Lei $n^{\circ} 12.846$ de $1^{\circ}$ de agosto de 2013. 2. O princípio da boa-fé e a ética corporativa. 3. Os desafios dos contratos empresariais em face da ética corporativa. 4. Considerações finais. Conclusão. Referências.

\section{INTRODUÇÃO}

Os fundamentos éticos apresentados à luz da análise da Lei 12.846 de $1^{\circ}$ de agosto de 2013 tem como premissa a consideração precípua trazida da era clássica, na qual fez parte dentre várias figuras da época, Adam Smith, o pai do liberalismo e da economia moderna. Neste contexto, podem-se mencionar os entendimentos indicados na obra "Riqueza das Nações" deste relevante liberalista, filósofo e economista cuja compreensão de ideal ainda se perpetua pelos séculos, como alicerce do pensamento contemporâneo desta sociedade capitalista no Estado Democrático de Direito que se instaurou. Sob este prisma, além disso, podem-se mencionar as condicionantes da era neoclássica que deu enfoque ao marginalismo de Marshall.

Diante disto, apresenta-se como de grande valor a consolidação da ética na sociedade hodierna sob todos os seus aspectos. A democracia é o elemento primordial na concretização de valores essenciais na coletividade, previstos na Constituição da República, que tem como escopo assegurar a justiça, a transparência e a equidade.

Sendo assim, dentre os diversos princípios previstos na Constituição da República, aquele que está em consonância com a ética é o da moralidade. Destaca-se que o embasamento ético-democrático proposto tem como objetivo esclarecer a aplicação da Lei n. $^{\circ}$ 12.846, de $1^{\circ}$ de agosto de 2013, muito conhecida, hodiernamente como "Lei Anticorrupção".
Além dos princípios constitucionais, essa lei fundamenta-se na Convenção sobre o Combate da Corrupção de Funcionários Públicos Estrangeiros em Transações Comerciais Internacionais pactuada pelo Brasil, na cidade de Paris, na França na data de 17 de dezembro de 1997. Sendo tal Convenção ratificada pelo Decreto Legislativo $\mathrm{n}^{\circ} 125$, de 14 de junho de 2000 e promulgada pelo Decreto presidencial $n^{\circ} 3678$, de 30 de novembro de $2000^{1}$.

Neste sentido, convém salientar que a lei supracitada, ainda não foi regulamentada, todavia, enfatiza-se que seu eixo central de segmento teve suas perspectivas estruturadas nas Leis Anticorrupção dos Estados Unidos da América - EUA (Foreign Corrupt Practices Act - FCPA) e do Reino Unido (UK Bribery Act $U K B A)$.

Destarte, a aplicação da nova obrigação legal revela o entrelaçamento entre o Público e Privado. Na dimensão do Direito Público tem o condão de asseverar que não se praticará atos contra a Administração Pública nacional e estrangeira. Já no que se refere a sua aplicação no âmbito privado, acentua-se a sua efetivação às pessoas jurídicas de Direito Privado indicadas na aludida lei. Para as corporações torna-se

\footnotetext{
1 BRASIL. Ministério da Justiça. Convenção sobre o Combate da Corrupção de Funcionários Públicos Estrangeiros em Transações Comerciais Internacionais (OCDE). Disponível em: http://portal.mj.gov.br/main.asp? $\mathrm{View}=\{$ CEAF6121 $-6220-$ 440A-A549-

983CFF943CCA $\} \&$ BrowserType $=$ IE \&LangID $=$ ptbr\&params=itemID\%3D\%7BD3474CB1-E214-45698D0603BA301D1093\%7D\%3B\&UIPartUID=\%7B2868BA3C1C72-4347-BE11-A26F70F4CB26\%7D. Acesso em 30 out. 2014.
} 
imprescindível a criação de normas éticas internas em suas organizações, repercutindo de modo direto nos contratos empresariais. Por este motivo, concretização da "Lei Anticorrupção" no ambiente corporativo é o tema eleito por este artigo, que passará a delineá-lo sob a perspectiva do princípio da boa-fé.

Para empreender essa tarefa, o trabalho utiliza-se do método dedutivo e do procedimento de pesquisa bibliográfico, partindo dos fundamentos da Lei Anticorrupção para, em seguida, indagar sobre sua aplicabilidade nos contratos empresariais. Segue-se um plano de trabalho divido em três partes: a primeira trata da Lei $n .^{\circ} 12.846$, de $1^{\circ}$ de agosto de 2013 e seus fundamentos constitucionais; a segunda trata do princípio da boa-fé e a ética corporativa que dele deriva; e a terceira apresenta a ética corporativa como um novo desafio para os contratos empresariais.

\section{FUNDAMENTOS CONSTITUCIONAIS DA LEI $N^{\circ} 12.846$ DE $1^{\circ}$ DE AGOSTO DE 2013}

O Estado Democrático de Direito, enunciado pela Constituição da República de 1988, elege como seu núcleo o princípio da dignidade da pessoa humana (artigo $1^{\circ}$, III), lançando os contornos de uma axiologia material, que se traduz no reconhecimento dos direitos fundamentais como garantia de condições ao livre desenvolvimento da personalidade humana. Neste contexto, inseremse os fundamentos da Lei $\mathrm{n}^{\mathrm{o}} 12.846 / 22013$, entrelaçando-se o princípio democrático e o princípio da moralidade administrativa.

O princípio democrático é delineado por José Afonso da Silva como um

[...] conceito histórico. Não sendo por si um valorfim, mas meio e instrumento de realização de valores essenciais de convivência humana que se traduzem basicamente nos direitos fundamentais do homem, compreende-se que a historicidade destes a envolva na mesma medida, enriquecendo-lhe o conteúdo a cada etapa do evolver social, mantido sempre o princípio básico de que ela revela um regime político em que o poder repousa na vontade do povo. Sob esse aspecto, a democracia não é um mero conceito político abstrato e estático, mas é um processo de afirmação do povo e de garantia dos direitos fundamentais que o povo vai conquistando no decorrer da história. ${ }^{2}$

Além disso, salienta o autor, que a democracia tem amparo na existência da conexão entre o povo e poder. Neste ínterim, relata José Afonso da Silva que esta se chama "poder político, poder econômico e poder social".

Sob este prisma, a democracia, ainda, segundo José Afonso da Silva é o:

[...] governo do povo, pelo povo e para o povo -
aponta para a realização dos direitos políticos, que
apontam para a realização dos direitos econômicos
e sociais, que garantem a realização de Direitos
individuais de que a liberdade é a expressão mais
importante. Os Direitos Econômicos e Sociais são
de natureza igualitária, sem os quais os outros não
se efetivam realmente. É nesse sentido que também
se pode dizer que os direitos humanos fundamentais
são valores de uma democracia. Vale dizer: ela
deve existir para realizá-los, com o que estará
concretizando a justiça social. ${ }^{3}$

Com isto, destaca o autor que a "democracia é o regime de garantia geral para a realização dos Direitos fundamentais do homem"4 . Por outras palavras, para além de uma democracia política, trata-se do princípio em seu aspecto material.

Ancorada nas teses do contratualismo moderno, a democracia delineou-se sobre a ideia de representação. $\mathrm{Na}$ medida em que a lei é expressão da vontade geral, a democracia encontrava inspiração na reivindicação política do liberalismo: proteger as liberdades individuais

\footnotetext{
${ }^{2}$ SILVA, José Afonso da. Curso de Direito Constitucional Positivo. 28. ed. São Paulo: Malheiros editores, 2007, p. 126.

${ }^{3}$ SILVA, José Afonso da. op. cit., p. 132.

${ }^{4}$ SILVA, José Afonso da. op. cit., Loc. Cit.
} 
contra o poder do Estado $^{5}$. Nessa direção, os direitos fundamentais de primeira geração constituem-se em afirmação do princípio democrático, como resultado da liberdade e dignidade dos cidadãos, expressas na vontade geral $^{6}$. Trata-se de uma cidadania tão somente formal, segundo a qual os cidadãos, abstraídos de suas desigualdades materiais, foram investidos de direitos políticos que se realizam na esfera pública.

Uma segunda geração de direitos, dotados de conotação econômica e social, testemunha o avanço do "fato democrático". Considerando-se que o privado não se opõe ao público, em nome do liberalismo, e nem mesmo o público ao privado, em favor do socialismo, assiste-se à pulverização da democracia política ${ }^{7}$. Por conseguinte, o princípio democrático volta-se do público para o privado e passa a exigir inclusão social, o que se traduz na existência de condições materiais mínimas para o exercício da cidadania $^{8}$. Eis que se trata de uma exigência inarredável do Estado Democrático de direito que o exercício das liberdades ocorra de modo efetivo, com vistas a alcançar a igualdade real e a justiça social ${ }^{9}$.

Sob este prisma, o princípio democrático insere-se dentre os fundamentos da Lei Anticorrupção ora apresentada, tendo em vista que o ser humano está inteiramente envolvido nos aspectos da referida lei em detrimento aos atos contra a administração pública. Nesta conjuntura, a coletividade é a detentora dos bens jurídicos protegidos por esta legislação, sendo que o fundamento para tanto é a efetiva aplicação da justiça social. Deste modo, cabe destacar ainda que o Estado Democrático de

${ }^{5}$ GOYARD-FABRE, op. cit., p. 278.

${ }^{6}$ GOYARD-FABRE, op. cit., p. 288.

${ }^{7}$ GOYARD-FABRE, op. cit., p. 300.

${ }^{8}$ SARMENTO, op. cit., p. 307.

9 SARLET, Ingo Wolfgang. A eficácia dos direitos fundamentais. 5. ed. Porto Alegre: Livraria do Advogado, 2005, p. 71-72.
Direito encontra-se na base da efetivação dos diretos dos cidadãos.

Nessa mesma diretriz, o artigo $3^{\circ}$, I da Constituição da República estabelece que um dos objetivos fundamentais da República Federativa do Brasil é a construção de uma sociedade livre, justa e solidária, fundamento para assegurar o respeito à dignidade da pessoa humana. Maria Celina Bodin de Moraes ocupa-se do substrato deste princípio, no qual se movem os princípios da igualdade, liberdade, solidariedade e integridade psicofísica, com vistas a conter sua utilização como ratio de todo e qualquer direito fundamental, presente na ordem pública ${ }^{10}$.

A dignidade da pessoa humana não é criação do constituinte, mas objeto de sua proteção, sendo elevada à condição de fundamento do Estado Democrático de Direito. E surgindo ainda como um critério de ponderação, que delimita a intensidade dos direitos fundamentais nas relações privadas. Por conseguinte, os contratos empresariais podem ter seus valores delimitados na esfera pública, sofrendo influência do princípio democrático, como ora se pretende. Eis que pondera Maria Celina Bodin de Moraes:

Nos Estados democráticos, é na esfera política que são conhecidos os valores comuns e estabelecidos os princípios fundamentais. $\mathrm{O}$ Direito Constitucional representa o conjunto de valores sobre os quais se constrói, na atualidade, o pacto da convivência coletiva, função que já foi exercida pelos códigos civis. À diferença, porém, da codificação, redigida pelos juristas à luz dos valores de uma classe dirigente, os textos constitucionais, ao menos tendencialmente, são elaborados por um legislador democrático. Desse modo, ignorar os princípios constitucionais, ou interpretá-los à luz do código civil, como ainda hoje, sob considerações variadas, alguns têm feito, significa desconsiderar o princípio da democracia ou tentar escamoteá-lo com a idéia de uma 'razão lógica', de um cientificismo obrigatório, ou apenas subordinar-se à força da tradição. ${ }^{11}$

10 MORAES, Maria Celina Bodin de. Danos à pessoa humana: uma leitura civil-constitucional dos danos morais. Rio de Janeiro: Renovar, 2003, p. 85.

${ }^{11}$ MORAES, Maria Celina Bodin de. op. cit., p. 70. 
Sob uma perspectiva ética, o princípio da moralidade também é decorrência da dignidade da pessoa humana, de tal modo que se afirma como um dos princípios da administração pública, que encontra previsão no artigo 37 da Constituição da República, asseverando José Afonso da Silva:

A ideia subjacente ao princípio é a de que a moralidade administrativa não é moralidade comum, mas moralidade jurídica. Essa consideração não significa necessariamente que o ato legal seja honesto. Significa como disse Hauriou, que a moralidade administrativa consiste "no conjunto de regras de conduta tiradas da disciplina interior da administração." [...] a moralidade administrativa não é meramente subjetiva, porque não é puramente formal, porque tem conteúdo jurídico a partir de regras e princípios da Administração. ${ }^{12}$

Convém ressaltar que o princípio da moralidade ora indicado, tem como fundamento a ética. Sendo assim, com base no princípio da moralidade pode-se dizer que este referencia o cumprimento da Lei $\mathrm{n}^{\mathrm{o}} 12.846$, de $1^{\mathrm{o}}$ de agosto de 2013 que dispõe acerca da responsabilização administrativa e civil de pessoas jurídicas pela prática de atos contra a administração pública, nacional ou estrangeira (denominada Lei Anticorrupção). Diante disto, cabe enfatizar o que preconiza a referida legislação:

Aplica-se o disposto nesta Lei às sociedades empresárias e às sociedades simples, personificadas ou não, independentemente da forma de organização ou modelo societário adotado, bem como a quaisquer fundações, associações de entidades ou pessoas, ou sociedades estrangeiras, que tenham sede, filial ou representação no território brasileiro, constituídas de fato ou de direito, ainda que temporariamente.

Art. $2^{\mathrm{o}}$ As pessoas jurídicas serão responsabilizadas objetivamente, nos âmbitos administrativo e civil, pelos atos lesivos previstos nesta Lei praticados em seu interesse ou benefício, exclusivo ou não.
Art. 3o A responsabilização da pessoa jurídica não exclui a responsabilidade individual de seus dirigentes ou administradores ou de qualquer pessoa natural, autora, coautora ou partícipe do ato ilícito.

$\S 1^{\text {o }}$ A pessoa jurídica será responsabilizada independentemente da responsabilização individual das pessoas naturais referidas no caput.

$\S 2$ o Os dirigentes ou administradores somente serão responsabilizados por atos ilícitos na medida da sua culpabilidade.

\begin{abstract}
Art. 4 ${ }^{\circ}$ Subsiste a responsabilidade da pessoa jurídica na hipótese de alteração contratual, transformação, incorporação, fusão ou cisão societária.

§ 1ํ Nas hipóteses de fusão e incorporação, a responsabilidade da sucessora será restrita à obrigação de pagamento de multa e reparação integral do dano causado, até o limite do patrimônio transferido, não lhe sendo aplicáveis as demais sanções previstas nesta Lei decorrentes de atos e fatos ocorridos antes da data da fusão ou incorporação, exceto no caso de simulação ou evidente intuito de fraude, devidamente comprovados.

$\S 2^{\mathrm{o}}$ As sociedades controladoras, controladas, coligadas ou, no âmbito do respectivo contrato, as consorciadas serão solidariamente responsáveis pela prática dos atos previstos nesta Lei, restringindo-se tal responsabilidade à obrigação de pagamento de multa e reparação integral do dano causado. ${ }^{13}$
\end{abstract}

Consoante Ubirajara Costódio Filho o objetivo da Lei 12.846 de $1^{\circ}$ de agosto de 2013 é o enfrentamento aos atos de corrupção contra a administração pública. Referido autor destaca que

[...] corromper é influenciar a conduta de alguém por meio de oferta de vantagem ou recompensa, com vistas a obter desse sujeito dada prestação indevida, de interesse do próprio agente corruptor ou de terceiro.

Infelizmente a corrupção é problema mundial atingindo e envolvendo governos, cidadãos, instituições e empresas públicas ou privadas, existindo desde tempos imemoriais. ${ }^{14}$

13 BRASIL. Lei $\mathrm{n}^{\mathrm{o}} 12.846$, de $1^{\mathrm{o}}$ de agosto de 2013. Disponível em:

<http://www.planalto.gov.br/ccivil_03/_ato20112014/2013/lei/l12846.htm>. Acesso em 20 out. 2014.

${ }^{14}$ SANTOS, José Anacleto Abuch Santos; BERTONCINI, Mateus; COSTÓDIO FILHO, Ubirajara. Comentários à

${ }^{12}$ SILVA, José Afonso da. op. cit., p. 668. 
A corrupção prejudica "o meio ambiente", a "livre concorrência e os consumidores", as "finanças públicas" o "comércio internacional", a "Democracia e a República" 15 . No que se refere ao prejuízo da corrupção à Democracia e à República, isto ocorre porque esta "torna a Administração Pública refém de interesses privados e minoritários, serviente apenas de grupos detentores de grande poder econômico, desviando os agentes públicos de sua função essencial de atendimento dos interesses coletivos, de modo isonômico." 16

Diante de todos os prejuízos advindos de atos de corrupção, tratar-se-á a respeito desta sob a perspectiva do princípio da boa-fé e o aspecto ético que dela deriva, para refletir sobre sua aplicabilidade aos contratos de Direito Privado.

\section{O PRINCÍPIO DA BOA-FÉ E A ÉTICA CORPORATIVA}

O Direito Contratual contemporâneo encontra-se dentre os desafios do Direito empresarial, na perspectiva da ética corporativa e da Lei $n^{\circ} 12.846$ de $1^{\circ}$ de agosto de 2013 (Lei Anticorrupção). Neste contexto, pode-se enfatizar o respeito aos princípios contratuais, que passam a ser expostos como fundamentais a qualquer relação contratual.

No contexto do Estado de Direito Liberal, o individualismo delineou o contrato como instrumento essencial para as relações humanas ao lado da propriedade. A vida econômica teria de ser vivida por meio de contratos, pois é pelo consentimento livre e espontâneo que os homens se interrelacionam. $\mathrm{O}$ contrato apoia-se, então, sobre dois princípios: a

Lei 12.846/2013: Lei Anticorrupção. São Paulo: Revista do Tribunais, 2014, p. 11.

${ }^{15}$ SANTOS, José Anacleto Abuch Santos; BERTONCINI, Mateus; COSTÓDIO FILHO, Ubirajara. op. cit., p. 15

${ }^{16}$ SANTOS, José Anacleto Abuch Santos; BERTONCINI, Mateus; COSTÓDIO FILHO, Ubirajara. op . cit., p. 15 liberdade contratual e a igualdade formal. Pelo primeiro, expressão da autonomia privada, o homem precisa ter a liberdade de agir para satisfação dos seus interesses particulares. E o meio técnico-jurídico para fazê-lo é o contrato, utilizando-se da mais ampla liberdade de escolher contratar ou não, com quem fazê-lo, e de estabelecer suas cláusulas. Mas a liberdade contratual só é possível se houver igualdade entre as partes, por isso o equilíbrio contratual revelou-se apenas como formal, pois não interessavam as desigualdades sociais e econômicas que cercavam as partes. Tais princípios restaram desmentidos pela constante desigualdade substancial nas relações contratuais.

Em razão dessa situação, o Estado Social de Direito promoveu um processo de limitação da liberdade contratual, com vistas a restaurar a igualdade no contrato, que passou a ser substancial, por meio de uma crescente intervenção do Estado, e que se denominou de dirigismo contratual. Assim, diversos princípios que até então cercavam os contratos foram relativizados, com vistas a limitar o poder de auto-regulação dos próprios interesses, conferidos pela autonomia privada.

Compõe-se um cenário favorável à compreensão de novos princípios contratuais: com vistas a ultrapassar os limites de uma teoria contratual clássica, a boa-fé em sua vertente objetiva ${ }^{17}$ é um dos principais instrumentos

\footnotetext{
17 Asseverando tratar-se de duas boas-fés, que suscitam confiança própria e a confiança no outro, Fernando NORONHA acolhe a distinção: “[...] de forma similar à subjetiva, também a boa-fé objetiva tem na sua base uma idéia de confiança, a necessidade de tutelar esta. Só que, enquanto na boa-fé subjetiva se tutela a confiança de quem acredita numa situação aparente, na objetiva tutela-se a de quem acreditou que a outra parte procederia de acordo com os padrões de conduta exigíveis. Como se vê, em ambas existe um elemento subjetivo, representado pela confiança de alguém que acreditou em algo, mas só na boa-fé objetiva existe um segundo elemento, que é o dever de conduta de outrem". (NORONHA, Fernando. O direito dos contratos e seus princípios fundamentais (autonomia
} 
utilizados pelos juízes para construção de uma teoria contratual contemporânea, tornando presente as palavras de Clóvis do Couto e Silva:

Em nossos dias, cresceu extraordinariamente em importância o da boa fé, em virtude da revisão por

privada, boa-fé, justiça contratual). São Paulo : Saraiva, 1994, p. 136)

Atentando para a distinção, Judith Martins-Costa acrescenta, acerca da boa-fé subjetiva: "Pode denotar, ainda, secundariamente, a idéia de vinculação ao pactuado, no campo específico do direito contratual, nada mais aí significando do que um reforço ao princípio da obrigatoriedade do pactuado, de modo a se poder afirmar, em síntese, que a boa-fé subjetiva tem o sentido de uma condição psicológica que normalmente se concretiza no convencimento do próprio direito, ou na ignorância de se estar lesando direito alheio, ou na adstrição 'egoística' à literalidade do pactuado." (MARTINS-COSTA, Judith. A boa-fé no direito privado: sistema e tópica no processo obrigacional. São Paulo: Revista dos Tribunais, 1999. p. 412.) Por vezes, esse será o sentido de boa-fé "subjetivada" ao qual se fará referência no decorrer do trabalho.

No direito comparado, António Menezes Cordeiro ensina que a boa-fé subjetiva refere-se a um estado relativo ao sujeito de direito, enquanto a boa-fé objetiva surge como algo que lhe é exterior. Porém, atenta, que: "A contraposição entre a boa-fé objectiva e a subjectiva, ao contrário do resultante de alguma literatura, não se confunde com uma outra, entre boa fé psicológica e ética. Ambos estes termos abrem na boa fé subjectiva: o primeiro, traduz um estado fáctico de mera ignorância, [...] o segundo, manifesta um estado de ignorância valorado pelo Direito, com reflexos práticos em que revela, apenas, se for desculpável [...]" (CORDEIRO, António Menezes. Da boa fé no direito civil. Coimbra: Almedina, 1997, p. 24)

Afirmando essa dualidade, mas sem descuidar do sentido ético que presidem ambas as vertentes, está José Luiz de los Mozos: “[...] ambas concepciones, respondiendo a un fondo ético común aunque acabe manifestándose en una disposición psicológica: creencia de no dañar a otro, que tiene en todo caso un fundamento ético, concepción que es la que la venido a prevalecer en la doctrina..." (LOS MOZOS, José Luiz de. El principio de la buena fe. Sus aplicaciones práticas en el Derecho Civil Español. Barcelona : Bosch, [s. d.]. p. 39) Trata-se do sentido unitário para o qual aponta sua concepção, enquanto princípio geral do direito, ao qual se refere Delia Matilde Ferreira Rubio: recolhendo os ensinamentos de António Hernandes GIL, assevera a autora, que ao identificar-se a objetividade com a normatividade, a boa-fé é objetiva porque representa uma diretriz de comportamento. A boa-fé subjectiva nada mais é do que um comportamento concreto à luz de um comportamento exigido em abstrato pela boa-fé objetiva. (RUBIO, Delia Matilde Ferreira. La buena fe. El principio general en el derecho civil. Madrid: Montecorvo, 1984. p. 94) que passou a teoria geral das obrigações, sob o influxo de novas tendências jurisprudenciais e doutrinárias, motivadas, em grande parte, por uma vigorosa reação às concepções do positivismo jurídico. ${ }^{18}$

No contexto do Estado Social de Direito, que se orientou pelo princípio da dignidade da pessoa humana, retiram-se os entraves à intervenção do juiz no reino da vontade individual, e o julgador procede ao reenvio extrasistemático, com vistas a recolher valores para a criação da norma de conduta que se impõe às partes e estabelecer suas consequências. Delineia-se um novo percurso da boa-fé, que subtraída do formalismo em que estava mergulhada, supera o voluntarismo jurídico: novas figuras são criadas e princípios antes obscurecidos pelo dogma da vontade ganham vigor.

Promove-se o delineamento de uma jurisprudência suficientemente adulta para preenchê-las de uma nova ética jurídica e social, ${ }^{19}$ no interior da qual o princípio da boa-fé cumpre com uma função "harmonizadora", conciliando-se, assim, o "rigorismo lógicodedutivo de ciência do Direito do século passado com a vida e as exigências éticas atuais". ${ }^{20}$ Proclama-se como um "direito equitativo", contestando e, por vezes, rompendo com o direito estrito, atuando na "transformação da moral econômica liberal numa outra adequada às idéias do Estado social" ${ }^{21}$. Pela via de um "direito judicial", novos fatos e valores adentram no direito, diante da alteração da conjuntura econômica e social.

Em atenção à primeira dessas funções, a boa-fé objetiva age como um "topos subversivo", pondera Judith Martins-Costa,

${ }^{18}$ COUTO E SILVA, Clóvis Veríssimo do. A obrigação como processo. São Paulo: José Bushatsky, 1976. p. 15.

19 WIEACKER, Franz. História do direito privado moderno. 2. ed. Lisboa: Fundação Calouste Gulbenkian, 1997, p. 546.

${ }^{20}$ COUTO E SILVA, Clóvis Veríssimo do. op. cit., p. 42.

${ }^{21}$ WIEACKER. op. cit., p. 546. 
projetando novos contornos para a relação jurídica obrigacional, de estática à dinâmica. Tal concepção de obrigação demonstra que o esquema obrigacional não se esgota na soma de posições antagônicas, antes, encontra tradução em uma relação de cooperação entre credor e devedor, projetando ao lado dos deveres principais e secundários de prestação, deveres acessórios de conduta. Traduzidos na tríplice classificação lealdade, informação e proteção, tais deveres anexos ou instrumentais não decorrem da lei ou da vontade, mas da boa-fé. Estão presentes desde as tratativas, durante todo o contrato, e até mesmo, após sua conclusão, rompendo o dualismo da tipicidade da responsabilidade civil em contratual e extracontratual, para novas formas como as responsabilidades pré e pós-contratual.

Com vistas a determinar o alcance dos direitos e obrigações das partes em sua função hermenêutica, a boa-fé rompe o dogma da vontade. Eis que a tutela desloca-se do declarante para a confiança gerada no destinatário pela manifestação de vontade. Nessa ordem de ideias, interpretar o contrato segundo a boa-fé é optar pelo sentido que seja mais favorável à parte débil do contrato, que propicie a conservação deste último, ou que aquele princípio aponte como o mais razoável.

Em sua função de equilíbrio, a boa-fé quebra a intangibilidade contratual e relativiza o pacta sunt servanda. A destruição da relação de equivalência entre as prestações e o desaparecimento do fim essencial do contrato permitem a revisão e, por vezes, a resolução do contrato. Eis que rompem o equilíbrio tutelado pela boa-fé e pela justiça contratual substancial.

Sob a função de controle ao exercício de direitos, o voluntarismo jurídico sucumbe à boafé, uma vez que tal exercício mostra-se inadmissível quando contraria a confiança gerada na contraparte, constituindo-se em um venire contra factum proprium. Trata-se de uma nova roupagem impressa pela boa-fé à figura do abuso do direito. Isso se torna mais visível em seu papel de controle ao exercício de prerrogativas individuais: exceptio doli generalis, venire contra factum proprium, verwirkung, erwirkung, tu quoque, a alegabilidade de nulidades formais e o exercício desequilibrado de direitos ganham prestígio como modalidades típicas de exercício inadmissível de posições jurídicas.

$\mathrm{Na}$ codificação de 2002 promove-se o relançamento daquele princípio sob a moldura de uma cláusula geral, no artigo 422: "Os contratantes são obrigados a guardar, assim na conclusão do contrato, como em sua execução, os princípios de probidade e boa-fé". A boa-fé ainda é acolhida em suas funções interpretativa e de controle ao exercício de prerrogativas individuais: o artigo $113^{22}$ representa uma superação da teoria da vontade na orientação da interpretação do contrato, e consequente tutela da confiança da contraparte. E como forma de especificar tal tutela, acolhe-se no artigo $423^{23}$ a interpretação do contrato de adesão de modo mais favorável ao aderente, o que se constitui em positivação de construção jurisprudencial. Do artigo $170{ }^{24}$ pode-se extrair a regra de interpretação que favoreça a conservação do contrato, que também se fundamenta na boa-fé. A função de controle é acolhida no artigo $187,{ }^{25}$ sob os moldes do Código Civil português e seu artigo 334 .

\footnotetext{
${ }^{22}$ Art. 113. Os negócios jurídicos devem ser interpretados conforme a boa-fé e os usos do lugar de sua celebração.

23 Art. 423. Quando houver no contrato de adesão cláusulas ambíguas ou contraditórias, dever-se-á adotar a interpretação mais favorável ao aderente.

${ }^{24}$ Art. 170 . Se, porém, o negócio jurídico nulo contiver os requisitos de outro, subsistirá este quando o fim a que visavam as partes permitir supor que o teriam querido, se houvessem previsto a nulidade.

${ }^{25}$ Art. 187. Também comete ato ilícito o titular de um direito que, ao exercê-lo, excede manifestamente os limites impostos pelo seu fim econômico ou social, pela boa-fé ou pelos bons costumes.
} 
Mantendo consigo a estrutura do Código anterior, ora reclama-se do intérprete a atividade de preenchimento dessas cláusulas abertas com novos valores, fazendo-se do jurista um engenheiro social e, prestando-se para tanto, a princípiologia constitucional, que se mostra como uma pauta importante, mas não exclusiva. Neste sentido, adverte Gustavo Tepedino, que "[...] as cláusulas gerais do novo Código Civil poderão representar uma alteração relevante no panorama do direito privado brasileiro desde que lidas e aplicadas segundo a lógica da solidariedade constitucional e da técnica interpretativa contemporânea." 26

O princípio da boa-fé suscita um comportamento ético, honesto, dotado de probidade em todos os contratos regidos pelo Código Civil, nestes incluídos os contratos empresariais. Eis que o artigo 422 localiza-se no capítulo das disposições gerais do título "dos contratos em geral", enquanto o livro do Direito da Empresa situa-se na parte especial do Código, ensejando uma unificação parcial do Direito Privado. Sendo assim se pode afirmar que, à luz da Lei Anticorrupção, enseja-se o afastamento de qualquer ato de corrupção. A ética, para além de um dever moral, deve se apresentar como um dever jurídico que fundamenta uma relação salutar entre as partes contratantes, de modo que ambas permaneçam agindo de forma incorruptível. Pode-se afirmar que deriva do princípio da boa-fé um dever acessório de conduta que impõe aos contratantes uma nova honestidade contratual: agir de forma incorruptível ou abster-se da pratica de atos que contrariam a nova lei. Trata-se de uma nova ética, imprescindível aos contratos empresariais: a ética corporativa.

Nos dias atuais, muitas são as situações em que ocorre a infração ao princípio da boa-fé,

\footnotetext{
${ }^{26}$ TEPEDINO, Gustavo (Coord.). A parte geral do novo Código Civil. Estudos na perspectiva civil-constitucional. Rio de Janeiro: Renovar, 2002, p. XX.
}

em decorrência de atos de corrupção constatados durante o período de vigência contratual. No âmbito corporativo, com embasamento no que dispõe a Lei Anticorrupção pode-se destacar que nos contratos pactuados com a administração pública, tal conduta corrupta, como previsão na referida lei é infração e é passível de sanção, conforme se apresenta nos artigos $5^{\circ}, 6^{\circ}$ e $7^{\circ}$ da Lei ${ }^{\circ} 12.846 / 2013$ :

Art. 5o Constituem atos lesivos à administração pública, nacional ou estrangeira, para os fins desta Lei, todos aqueles praticados pelas pessoas jurídicas mencionadas no parágrafo único do art. $1^{\circ}$, que atentem contra o patrimônio público nacional ou estrangeiro, contra princípios da administração pública ou contra os compromissos internacionais assumidos pelo Brasil, assim definidos:

I - prometer, oferecer ou dar, direta ou indiretamente, vantagem indevida a agente público, ou a terceira pessoa a ele relacionada;

II - comprovadamente, financiar, custear, patrocinar ou de qualquer modo subvencionar a prática dos atos ilícitos previstos nesta Lei;

III - comprovadamente, utilizar-se de interposta pessoa física ou jurídica para ocultar ou dissimular seus reais interesses ou a identidade dos beneficiários dos atos praticados;

IV - no tocante a licitações e contratos:

a) frustrar ou fraudar, mediante ajuste, combinação ou qualquer outro expediente, o caráter competitivo de procedimento licitatório público;

b) impedir, perturbar ou fraudar a realização de qualquer ato de procedimento licitatório público;

c) afastar ou procurar afastar licitante, por meio de fraude ou oferecimento de vantagem de qualquer tipo;

d) fraudar licitação pública ou contrato dela decorrente;

e) criar, de modo fraudulento ou irregular, pessoa jurídica para participar de licitação pública ou celebrar contrato administrativo;

f) obter vantagem ou benefício indevido, de modo fraudulento, de modificações ou prorrogações de contratos celebrados com a administração pública, sem autorização em lei, no ato convocatório da licitação pública ou nos respectivos instrumentos contratuais; ou g) manipular ou fraudar o equilíbrio econômicofinanceiro dos contratos celebrados com a administração pública;

$\mathrm{V}$ - dificultar atividade de investigação ou fiscalização de órgãos, entidades ou agentes públicos, ou intervir em sua atuação, inclusive no 
âmbito das agências reguladoras e dos órgãos de fiscalização do sistema financeiro nacional.

$\S 1$ 을 Considera-se administração pública estrangeira os órgãos e entidades estatais ou representações diplomáticas de país estrangeiro, de qualquer nível ou esfera de governo, bem como as pessoas jurídicas controladas, direta ou indiretamente, pelo poder público de país estrangeiro.

$\S 2^{2}$ - Para os efeitos desta Lei, equiparam-se à administração pública estrangeira as organizações públicas internacionais.

$\S 3$ - Considera-se agente público estrangeiro, para os fins desta Lei, quem, ainda que transitoriamente ou sem remuneração, exerça cargo, emprego ou função pública em órgãos, entidades estatais ou em representações diplomáticas de país estrangeiro, assim como em pessoas jurídicas controladas, direta ou indiretamente, pelo poder público de país estrangeiro ou em organizações públicas internacionais.

\section{CAPÍTULO III DA RESPONSABILIZAÇÃO ADMINISTRATIVA}

Art. $6^{\circ} \mathrm{Na}$ esfera administrativa, serão aplicadas às pessoas jurídicas consideradas responsáveis pelos atos lesivos previstos nesta Lei as seguintes sanções:

I - multa, no valor de $0,1 \%$ (um décimo por cento) a $20 \%$ (vinte por cento) do faturamento bruto do último exercício anterior ao da instauração do processo administrativo, excluídos os tributos, a qual nunca será inferior à vantagem auferida, quando for possível sua estimação; e

II - publicação extraordinária da decisão condenatória.

$\S \quad 1^{\circ}$ As sanções serão aplicadas fundamentadamente, isolada ou cumulativamente, de acordo com as peculiaridades do caso concreto e com a gravidade e natureza das infrações.

§ 2ㅇ A aplicação das sanções previstas neste artigo será precedida da manifestação jurídica elaborada pela Advocacia Pública ou pelo órgão de assistência jurídica, ou equivalente, do ente público.

$\S 3$ - A aplicação das sanções previstas neste artigo não exclui, em qualquer hipótese, a obrigação da reparação integral do dano causado.

$\S 4^{\circ} \mathrm{Na}$ hipótese do inciso I do caput, caso não seja possível utilizar o critério do valor do faturamento bruto da pessoa jurídica, a multa será de R\$ $6.000,00$ (seis mil reais) a $\mathrm{R} \$ 60.000 .000,00$ (sessenta milhões de reais).

§ 5o A publicação extraordinária da decisão condenatória ocorrerá na forma de extrato de sentença, a expensas da pessoa jurídica, em meios de comunicação de grande circulação na área da prática da infração e de atuação da pessoa jurídica ou, na sua falta, em publicação de circulação nacional, bem como por meio de afixação de edital, pelo prazo mínimo de 30 (trinta) dias, no próprio estabelecimento ou no local de exercício da atividade, de modo visível ao público, e no sítio eletrônico na rede mundial de computadores.

$\S 6^{\circ}$ (VETADO).

Art. 7o Serão levados em consideração na aplicação das sanções:

I - a gravidade da infração;

II - a vantagem auferida ou pretendida pelo infrator;

III - a consumação ou não da infração;

IV - o grau de lesão ou perigo de lesão;

V - o efeito negativo produzido pela infração;

VI - a situação econômica do infrator;

VII - a cooperação da pessoa jurídica para a apuração das infrações;

VIII - a existência de mecanismos e procedimentos internos de integridade, auditoria e incentivo à denúncia de irregularidades e a aplicação efetiva de códigos de ética e de conduta no âmbito da pessoa jurídica;

IX - o valor dos contratos mantidos pela pessoa jurídica com o órgão ou entidade pública lesados; e $\mathrm{X}$ - (VETADO).

Parágrafo único. Os parâmetros de avaliação de mecanismos e procedimentos previstos no inciso VIII do caput serão estabelecidos em regulamento do Poder Executivo federal.

Cabe destacar a importância da Lei $\mathrm{n}^{\circ}$ $12.846 / 2013$ de modo a coibir tais práticas corruptas, a fim de garantir a plena eficácia do princípio da moralidade, tendo como fundamento primordial a ética. No âmbito empresarial é possível denominá-la de ética corporativa, sendo de grande relevância para que condutas que contrariem a disposição legal não ocorram. O desafio nesse âmbito será a concretização de condutas corruptas que contrariem a boa-fé objetiva e revelem o conteúdo da cláusula geral do artigo 422 do Código Civil. Logo, se faz de suma importância a aplicação de regras internas nas empresas, com a elaboração dos denominados Código de Ética Conduta e de Compliance e Anticorrupção.

\section{OS DESAFIOS DOS CONTRATOS EMPRESARIAIS EM FACE DA ÉTICA CORPORATIVA}

O termo "contrato" pode ser usado para designar a materialidade expressa na atividade de 
aquisição ou troca de bens e serviços, ao mesmo tempo em que aparece nos textos legais ou nas sentenças dos juízes, em sua acepção técnicojurídica. Ocorre que essa dualidade traz consigo os contornos das relações que se estabelecem entre contrato e operação econômica. Não é possível se dizer que aquele é simplesmente identificável a esta última e, tampouco, que o contrato é uma categoria jurídica construída como um fim em si mesmo. Mas é possível afirmar com Enzo Roppo, que "o contrato é a veste jurídico-formal de operações econômicas", de tal modo, que "onde não há operação econômica, não pode haver também contrato". ${ }^{27}$ Trata-se de construção jurídica que é elaborada, tendo em vista e em função o conceito de operação econômica, o que lhe imprime um caráter instrumental em relação a esta última ${ }^{28}$.

A localização sistemática do contrato na codificação francesa de 1804, dentre os "diversos modos de aquisição da propriedade", revela o papel que lhe foi traçado pela civilística clássica. Assume "posição não autónoma, mas subordinada, servil, relativamente à propriedade". ${ }^{29}$ Considerando-se esta última como a "categoria-chave" das codificações modernas, outorgou-se ao contrato o papel de "libertação e mobilização da propriedade fundiária", ${ }^{30}$ em um contexto de capitalismo nascente por oposição à economia pouco dinâmica, traçada por uma estática feudal:

Mas contrato baseado no consenso significava, por
outro lado, uma forte garantia para as velhas classes
proprietárias (...) a garantia de que para a
transferência dos seus bens era sempre necessária a
sua vontade. (...) O princípio do consenso como
produtor, por si só, do vínculo jurídico, favorecia a
classe mercantil na sua relação com os proprietários
dos recursos e, ao mesmo tempo, protegia os
proprietários, impedindo que estes pudessem ser

${ }^{27}$ ROPPO, Enzo. O contrato. Tradução de Ana Coimbra e M. Januário C. Gomes. Coimbra: Almedina, 1988, p. 11.

${ }^{28}$ ROPPO. op. cit., p. 9-10.

${ }^{29}$ ROPPO. op. cit., p. 42.

${ }^{30}$ ROPPO. op. cit., p. 44. privados dos seus bens contra a sua própria vontade. $^{31}$

No século $\mathrm{XX}$, as relações entre contrato e propriedade desfizeram-se deste nexo de subordinação e instrumentalidade. Com o avanço do modo capitalista de produção, as formas de riquezas não se identificam mais com as coisas materiais, retirando-se a propriedade, especialmente, a imobiliária, do lugar de supremacia que ocupava no contexto liberal das codificações modernas.

A riqueza passa a ser depositada nos bens imateriais, como as marcas e patentes, concluindo um processo de "mobilização e desmaterialização da riqueza". ${ }^{32} \mathrm{O}$ contrato despe-se de um papel instrumental, meramente servil, subordinado à propriedade. À medida que esses bens imateriais tornam-se assimiláveis a coisas, o crédito torna-se objeto do patrimônio do credor, passível de ser transmitido. $\mathrm{O}$ contrato não se limita mais a transmitir a propriedade, antes a constitui, caracterizando-se como uma fonte geradora de riquezas, de tal modo, a afirmar Enzo Roppo: "parece ser o contrato, e já não a propriedade, o instrumento fundamental de gestão de recursos e propulsão da economia". ${ }^{33}$

A relevância atribuída ao "perfil dinâmico da actividade" corresponde ao papel assumido pelo conceito de empresa na propulsão do processo econômico, segundo Enzo Roppo ${ }^{34}$. De outra feita, o contrato adquire um papel cada vez mais relevante como "instrumento indispensável ao desenvolvimento profícuo e eficaz de toda a actividade económica organizada" 35 . Eis que o exercício da atividade empresarial é essencialmente coletivo, sendo a sociedade sua estrutura típica, o que lhe rende os contornos de uma estrutura contratual, de tal modo que participar desta atividade organizada significa

\footnotetext{
${ }^{31}$ ROPPO. op. cit., p. 46.

${ }^{32}$ ROPPO. op. cit., p. 64.

${ }^{33}$ ROPPO. op. cit., p. 66.

${ }^{34}$ ROPPO. op. cit., p. 66.

${ }^{35}$ ROPPO. op. cit., p. 67.
} 
hoje participar de um contrato. Este é o instrumento indispensável à realização das relações internas e externas da atividade empresarial, sendo que participar de suas relações se traduz em ser parte em um ou mais contratos $^{36}$.

Nesse contexto, a disciplina contratual adéqua-se ao direito empresarial, salientando-se a relevância da uma ética corporativa que tem como foco os gestores das empresas, seus colaboradores e prestadores de serviços. José Antonio Pupim Oliveira opina no sentido que por mais que uma empresa não possua capacidade de discernimento ético, visto que ela é amoral, suas ações podem ser observadas sob a perspectiva ética. A Ética dentro de uma empresa abrangeria os princípios utilizados dentro da organização, nisto incluindo as condutas dos gestores e as normas de cunho social e corporativo.

Muitas corporações possuem verdadeiros códigos de Ética aplicados às suas diretrizes. Neste ínterim, traz Robert Henry Srour uma lista de temas que fazem parte do conteúdo dos códigos de ética das empresas:

a.Relacionamento com os clientes, acionistas, colaboradores, fornecedores, prestadores de serviços, distribuidores, autoridades governamentais, órgãos reguladores, mídia, concorrentes, sindicatos, comunidades locais, terceiro setor, associações empresariais;

b.Conflito de interesse entre vários públicos de interesse;

c.Regulamentação da troca de presentes, gratificações, favores, cortesias, brindes, convites de fornecedores ou clientes.

d.Observância das leis vigentes.

e.Segurança e confidencialidade das informações não-públicos, em especial, das informações privilegiadas.

f. Teor dos balanços, das demonstrações financeiras e dos relatórios da diretoria endereçados aos acionistas, e seu nível de transparência.

g.Propriedade intelectual dos bens simbólicos, patentes e marcas.

\footnotetext{
${ }^{36}$ ROPPO. op. cit., p. 67-68.
}

h.Espionagem econômica ou industrial versus pesquisas tecnológicas e de uso de benchmarking e da inteligência competitiva.

i. Postura diante do trabalho infantil e do trabalho forçado.

j. Formação de lobbies ou tráfico de influência.

k.Formação de cartéis e participação em associações empresariais.

1. Contribuição para campanhas eleitorais;

m. Prestação de serviços profissionais por parte dos colaboradores a fornecedores, prestadores de serviços, clientes ou concorrentes.

n.Respeito aos direitos do consumidor.

o.Relação com o meio ambiente: uso de energia, água e papel; consumo de recursos naturais; poluição do ar; disposição final de resíduos.

p.Uso do tempo de trabalho para assuntos pessoais. q.Uso do nome da empresa para vantagens pessoais.

r. Discriminação das pessoas em função de gênero, etnia, raça religião, classe social, idade, orientação sexual, incapacidade física ou qualquer outro atributo, e regulação de sua seleção e promoção (questão da diversidade social).

s. Assédio moral e assédio sexual ${ }^{37}$.

\section{Enfatiza ainda o autor Robert Henry Srour} que de forma estratégica as empresas devem possuir um mecanismo de regulamentação das condutas, com a finalidade de aplicação da Ética em seu âmbito. $\mathrm{O}$ autor relaciona condutas que devem ser empregadas:

a) Prestação de contas de forma clara para com os acionistas, investidores e analistas de mercado, órgão reguladores e entidades capitais, tanto nacionais quanto internacionais. Com o fornecimento de informações límpidas, exatas, acessíveis, justa e completa.

b) Constituir um Comitê de Auditoria que, para garantir decisões confiáveis, exercite controles internos, fiscalize a gestão e os procedimentos, funcione para os acionistas como canal para o encaminhamento de questionamentos das ações da Administração, proceda à Avaliação do gerenciamento de negócios e desenvolva uma preocupação estratégica para proteger o patrimônio e a reputação da empresa.

c) Informar os clientes de forma correta, compreensível, fundamentada e tempestiva sobre as qualidades do produto ou do serviço oferecido, bem como sobre as condições e os riscos que afetam as

37 SROUR, Robert Henry. Ética Empresarial: O ciclo virtuoso dos negócios. 3. ed. Rio de Janeiro: Campus, 2008, p. 267. 
operações, para que eles disponham de informações fidedignas e, em consequência, possam estabelecer comparativos entre as várias opções disponíveis e possam tomar decisões com liberalidade de escolha e fundada segurança.

d) Aplicar medidas preventivas contra fraudes e divulgar sua eficácia para reter e consolidar a confiança conquistada junto aos clientes.

e) Impedir a utilização da instituição para legitimar recursos de origem criminosa - tal como a lavagem de dinheiro - e informar os gestores competentes a respeito de qualquer proposta de operação suspeita ou de situação prevista em regulamento competente.

f) Preservar a integridade dos documentos sob guarda, porque a memória da empresa e as bases dos lançamentos contábeis se encontram nos registros e nos relatórios que fundamentam os comunicados ao mercado, além de atender aos compromissos com os órgãos governamentais.

g) Elaborar demonstrativos financeiros de acordo com os princípios fundamentais da contabilidade dos países em que opera, além de manter um padrão que os trone comparáveis e auditáveis.

h) Conceder créditos às empresas, valorizando critérios socioambientais para que os projetos financiados reflitam as melhores práticas de gestão ambiental, em obediência aos Princípios do Equador, cujo objetivo consiste em garantir sustentabilidade, o equilíbrio ambiental, o impacto social e a prevenção de tudo o que possa causar embaraços no transcorrer dos empreendimentos.

i) Elaborar uma política de Chinese Wall que defina os escudos protetores, as zonas de confinamento, os mecanismos de monitoramento e as barreiras que impeçam ou restrinjam o fluxo das informações não-públicas cuja difusão constitui fonte potencial de conflitos de interesses entre as áreas internas da instituição financeira e seus demais públicos de interesse;

j) Fazer recomendação aos clientes desde que adequadas à sua situação financeira e a seu perfil de investidores.

k) Selecionar os parceiros de negócios a partir do conhecimento da origem de seus recursos, bem como da atividade que exercem para prevenir a ocorrência de atos ilícitos cujas graves repercussões poderiam afetar a carreira dos profissionais, além de pôr em risco os ativos intangíveis da instituição.

1) Abster-se de aconselhar, difundir ou negociar com base em boatos [...] com base em rumores envolvendo negócios nacionais ou internacionais, no intuito de preservar a integridade das operações, resguardar a imagem corporativa e não disseminar uma cultura de especulação.

m) Rejeitar as operações que burlem norma legal ou regulamentar, inclusive fiscal, ainda que venham a valorizar carteira administrada, favoreçam os clientes, o próprio colaborador, terceiros e de seu relacionamento ou até mesmo instituição.

n) Evitar ficar inadimplente em negócios pessoais como, por exemplo, na emissão de cheques sem provisão de fundos ${ }^{38}$.

Dentre as condutas que devem ser regulamentadas, além das ressalvadas acima, que tratam de várias questões dentro da empresa, há a necessidade de uma regulamentação para um comportamento ético na esfera corporativa. De modo a assegurar condutas éticas na execução das atividades quaisquer que sejam.

$\mathrm{Na}$ elaboração de um código de ética nas empresas Robert Henry Srour descreve que há diferenças entre imposições administravas e condutas morais.

A regulação de condutas morais visa à aquisição da concordância ou adesão espontânea dos seus agentes. As normas administrativas por sua vez, processam-se por imposições legais ou outras exigências, pois se tratam de necessidades impreteríveis e improrrogáveis. Não obstante, quando se trata de diretrizes morais procura-se resguardar a empresa e seus profissionais do risco de reputação, mas dependem da pertinência dos seus fundamentos e da validade de suas recomendações.

$\mathrm{Na}$ elucidação dos conceitos, enfatiza o autor o que são questões relacionadas à Moral:

[...] as fraudes, os subornos e os conluios; as relações com os públicos de interesse; a observância das leis e das regulamentações; os conflitos de interesse entre o profissional e a empresa, a empresa e as partes interessadas; a diversidade social; a convivência entre superiores, pares e subordinados; assédio moral e assédio sexual; a confidencialidade das informações; o uso dos equipamentos da empresa; as ameaças à saúde e à segurança no trabalho; o posicionamento em relação aos negócios mantidos com entidades públicas; a problemática da espionagem econômica e a concorrência desleal etc ${ }^{39}$.

Robert Henry Srour resume que o código moral, é como um "manual de preceitos" éticos

\footnotetext{
${ }^{38}$ SROUR, Robert Henry. op. cit., p. 269 e 270.

${ }^{39}$ SROUR, Robert Henry. op. cit., p. 273.
} 
comportamentais. Um guia delineia os padrões de conduta no exercício profissional, um norte, uma meta moral.

Os códigos morais, conforme destaca o autor, são formados de duas formas, com a: Ética da convicção e a Ética da responsabilidade.

Sob o prisma da Ética da convicção, esta visa observar deveres, com o cumprimento por parte dos agentes de normas imperativas. "A teoria da convicção, cuja lógica consiste em cumprir voluntariamente deveres ou imperativos morais, acaba sendo confundida com uma abordagem político-jurídica cujas normas são impositivas, à semelhança das obrigações legais que se estribam em sanções disciplinares. Daí deriva uma concepção legalista dos códigos de conduta moral." ${ }^{40}$ Neste contexto, há imposição de normas "de fora para dentro" desprestigiando o caráter ético da adesão voluntária.

Por sua vez, a teoria da Ética da responsabilidade abrange normas que correspondem a recomendações justificadas, provenientes da análise de situações. $\mathrm{O}$ autor ressalta que poucos códigos possuem este nível de complexidade e modernidade.

No que tange à sociedade, a conduta ética de uma empresa deve estar pautada nas suas ações que visem o respeito à sociedade e ao meio ambiente. Ações éticas internas, também refletem a postura externa da empresa. Gerry Johnson, Kevan Scholes e Richard Whittington, compreendem que a posição ética de uma organização reflete que o grau que a empresa possui no cumprimento de suas obrigações com os stakeholders ${ }^{41} \mathrm{com}$ a sociedade como um todo. A postura ética de uma organização, como entendem os autores, revela o grau e caráter de

\footnotetext{
${ }^{40}$ SROUR, Robert Henry. op. cit., p. 273.

${ }^{41}$ Parte interessada. Organizações ou mesmo indivíduos interessados nas ações da empresa. OLIVEIRA, José Antonio Pupim. Empresas na Sociedade: Sustentabilidade e Responsabilidade Social. Rio de Janeiro: Elsevier, 2008.
}

uma empresa, bem como a maneira que ela é administrada.

Portanto, a responsabilidade social de empresa está em conexão direta com a ética, e conforme José Antonio Pupim Oliveira destaca uma empresa socialmente responsável é aquela que vai além de suas responsabilidades legais.

Por fim, tem-se a importância de se levar em consideração por parte das organizações da aplicação da ética corporativa. Com isto observase o resultado com reflexo em toda a empresa, com reconhecimento de toda a sociedade e cumprimento da legislação, principalmente no que tange ao execução das regras internas de Compliance para resguardar a empresa da ocorrência de qualquer ato que infrinja o disposto na Lei n. $^{\circ} 12.846$, de $1^{\circ}$ de agosto de 2013 - Lei anticorrup̧̧ão brasileira.

\section{CONCLUSÃO}

Nos dias atuais, sob a perspectiva da Lei $\mathrm{n}^{\circ}$ 12.846/2013 tem-se a ética como fundamento primordial da atual democracia, na perspectiva dos princípios contratuais na esfera corporativa.

Logo, dentre os diversos princípios estabelecidos na Constituição da República, a ética está em consonância com o princípio da moralidade. Sendo assim, os fundamentos constitucionais apresentados sob a égide do princípio democrático e da moralidade administrativa tem como objetivo esclarecer a aplicação da Lei n..$^{\circ} 12.846$, de $1^{\circ}$ de agosto de 2013, comumente nomeada como "Lei Anticorrupção".

Como se enfatizou, o fundamento legal da referida legislação adveio da Convenção sobre o Combate da Corrupção de Funcionários Públicos Estrangeiros em Transações Comerciais Internacionais ratificada pelo Decreto Legislativo $\mathrm{n}^{\circ} 125$, de 14 de junho de 2000 e 
promulgada pelo Decreto presidencial $n^{\circ} 3678$, de 30 de novembro de $2000^{42}$.

Neste sentido, destaca-se também que a lei supracitada, teve base também nas Leis Anticorrupção dos Estados Unidos da América EUA (Foreign Corrupt Practices Act - FCPA) e do Reino Unido (UK Bribery Act -UKBA).

Consoante relatado no presente artigo, as empresas, nos dias de hoje devem observar como imprescindível a criação de normas éticas internas tendo em vista os impactos da legislação, em especial nas questões dos contratos.

Enfatizou-se o princípio da boa-fé, que pressupõe fidelidade entre as partes, bem como observância de uma conduta proba. No aspecto da Lei $\mathrm{n}^{\circ} 12.846 / 2013$, mostra-se relevante a atenção desta de modo a afastar qualquer realização de ato de corrupção. Para tanto, é até mesmo possível considerá-lo como contrário a um dever acessório de conduta emanado daquele princípio, contribuindo com o conteúdo da cláusula geral do artigo do Código Civil.

Pelo exposto, a ética é o fundamento para que a relação entre as partes contratantes permaneça íntegra. Não obstante a importância da elaboração de códigos de condutas pelas empresas, o princípio da boa-fé pode ser aplicado aos contratos empresariais, ensejando a ética corporativa. Eis que se reconhece a importância desses contratos em um contexto cuja principal forma de riqueza é atividade empresarial.

\footnotetext{
42 BRASIL. Ministério da Justiça. Convenção sobre o Combate da Corrupção de Funcionários Públicos Estrangeiros em Transações Comerciais Internacionais (OCDE). Disponível em: http://portal.mj.gov.br/main.asp? View $=\{$ CEAF6121-6220440A-A549-

983CFF943CCA $\} \&$ BrowserType=IE $\&$ LangID=pt-

br\&params=itemID\%3D\%7BD3474CB1-E214-4569-

8D06-

03BA301D1093\%7D\%3B\&UIPartUID=\%7B2868BA3C-

1C72-4347-BE11-A26F70F4CB26\%7D. Acesso em 30 out. 2014.
}

Por derradeiro, normas de condutas éticas em âmbito corporativo, compliance $\mathrm{e}$ anticorrupção são os desafios atuais às empresas para não ocorram infrações à Lei 12.846/2013. 


\section{REFERÊNCIAS}

AGUILAR, Francis J. A Ética nas Empresas. Rio de Janeiro: Jorge Zahar, 1996.

AMATO, Lucas Fucci. Constitucionalização Corporativa: diretos humanos fundamentais, economia e empresa. Curitiba: Juruá, 2014.

BRASIL. Ministério da Justiça. Convenção sobre o Combate da Corrupção de Funcionários Públicos Estrangeiros em Transações Comerciais Internacionais (OCDE). Disponível em: <http://portal.mj.gov.br/main.asp?View= CEAF6121-6220-440A-A549-

983CFF943CCA $\} \&$ BrowserType=IE\&LangID=pt-br\&params=itemID\%3D\%7BD3474CB1-E2144569-8D06-03BA301D1093\%7D\%3B\&UIPartUID=\%7B2868BA3C-1C72-4347-BE11A26F70F4CB26\%7D>. Acesso em 30 out. 2014.

CORTINA, Adela; NAVARRO, Emilio Martinez. Ética. São Paulo: Edições Loyola, 2005.

COUTO E SILVA, Clóvis Veríssimo do. A obrigação como processo. São Paulo: Bushatsky, 1976.

GOYARD-FABRE, Simone. O que é democracia? Tradução de Claudia Berliner. São Paulo: Martins Fontes, 2003.

LEITE, Carlos Henrique Bezerra. Manual de Direitos Humanos. 3. ed. São Paulo: Atlas: 2014.

LOS MOZOS, Jose Luis de. El principio de la buena fe. Sus aplicaciones práticas en el Derecho Civil Español. Barcelona: Bosch, (s. d.).

MARTINS-COSTA, Judith. A boa-fé no direito privado: sistema e tópica no processo obrigacional. São Paulo: Revista dos Tribunais, 1999.

MENEZES CORDEIRO, António. Da boa fé no direito civil. Coimbra: Almedina, 1997.

MONTORO FILHO, André Franco. Corrupção, Ética e Economia. Rio de Janeiro: Elsevier; São Paulo: ETCO, 2012.

MORAES, Maria Celina Bodin de. Danos à pessoa humana: uma leitura civil-constitucional dos danos morais. Rio de Janeiro: Renovar, 2003.

NORONHA, Fernando. O direito dos contratos e seus princípios fundamentais (autonomia privada, boa-fé, justiça contratual). São Paulo: Saraiva, 1994.

OLIVEIRA, José Antonio Pupim. Empresas na Sociedade: Sustentabilidade e Responsabilidade Social. Rio de Janeiro: Elsevier, 2008.

PROCÓPIO. Argemiro. Subdesenvolvimento sustentável. 3. ed. Curitiba: Juruá, 2009.

ROPPO, Enzo. O contrato. Tradução de Ana Coimbra e M. Januário C. Gomes. Coimbra: Almedina, 1988.

RUBIO, Delia Matilde Ferreira. La buena fe. El principio general en el derecho civil. Madrid: 
Montecorvo, 1984.

SANTOS, José Anacleto Abuch Santos; BERTONCINI, Mateus; COSTÓDIO FILHO, Ubirajara. Comentários à Lei 12.846/2013: Lei Anticorrupção. São Paulo: Revista dos Tribunais, 2014.

SARLET, Ingo Wolfgang. A eficácia dos direitos fundamentais. 5. ed. Porto Alegre: Livraria do Advogado, 2005.

SARMENTO, Daniel. Direitos fundamentais e relações privadas. 2. ed. Rio de Janeiro: Lúmen Júris, 2006.

SILVA, José Afonso da. Curso de Direito Constitucional Positivo. 28. ed. São Paulo: Malheiros editores, 2007.

SROUR, Robert Henry. Ética Empresarial: O ciclo virtuoso dos negócios. 3. ed. Rio de Janeiro: Campus, 2008.

. Poder, Cultura e Ética nas Organizações. 3. ed. Rio de Janeiro: Campus, 2012.

TEPEDINO, Gustavo. (Coord.). A parte geral do novo Código Civil. Estudos na perspectiva civilconstitucional. Rio de Janeiro: Renovar, 2002.

VERGARA, Sylvia Constant; BRANCO; Paulo Durval. Empresa Humanizada e Organização Necessária é Possível. Scielo. Disponível em: 〈http://www.scielo.br/pdf/rae/v41n2/v41n2a03.pdf >. Acesso em 30 out. 2014.

WIEACKER, Franz. História do direito privado moderno. 2. ed. Lisboa: Fundação Calouste Gulbenkian, 1997.

Recebido em: 30/09/2016

Aceito em: 28/12/2016 
